\title{
Facets of biodiversity: a contemplative paradigm on ecosystem services
}

\section{Background}

Biodiversity alludes to assortment and changeability of life on earth; ordinarily measures variety at hereditary, species, and biological community level. ${ }^{1}$ Biodiversity is abound to the equator, ${ }^{2}$ inferable from warm atmosphere and high essential profitability. ${ }^{3}$ Biodiversity is most extravagant in the tropics; covers 10 percent of earth's surface, and around 90 percent of the world's species. ${ }^{4}$ Biodiversity will in general a bunch in hotspots, ${ }^{5}$ and has been expanding through time, ${ }^{6,7}$ and it is probably going to be decreased sooner rather than later. ${ }^{8}$ The development of people has assumed a key job in biodiversity decay joined by loss of hereditary decent variety. Human effects cause biodiversity loss essentially, and prevalently the territory pulverization. ${ }^{9}$

\section{Etymology and types}

Biodiversity is the most predominant term, which replaces the old customary words for example species assorted variety and species lavishness. Biodiversity is characterized as the "an agglomerate of qualities, species and biological systems of a specific district. ${ }^{10,11}$ The traditional types of biodiversity (biological diversity) are:

Taxonomic diversity (measures the species diversity)

Ecological diversity (measures the ecosystem diversity)

Morphological diversity [stems from genetic diversity and molecular diversity $],{ }^{12}$ and

Functional diversity (measure of the number of functionally different species within a population. ${ }^{13}$

There are different meanings of the term "Biodiversity". The 1992 United Nations Earth Summit characterized "Natural Diversity" as "the fluctuation among living beings from all sources, including, 'entomb alia', earthbound, marine and other sea-going biological communities, and the environmental edifices of which they are part: this incorporates assorted variety inside species, among species and of environments. ${ }^{14}$ This definition is utilized in the United Nations Convention on Biological Diversity. According to Gaston et al., ${ }^{15}$ biodiversity is "variety of life at all dimensions of natural association". Biodiversity can likewise be characterized hereditarily as the assorted variety of alleles, qualities, and creatures. ${ }^{16}$

\section{Distribution}

Biodiversity isn't uniformly disseminated; rather it differs significantly over the globe just as inside districts. Among different elements, the decent variety of every living thing (biota) relies upon temperature, precipitation, elevation, soils, geology, and the nearness of different species. The investigation of the spatial appropriation of living beings, species and environments, is the art of biogeography. It reliably measures higher in the tropics, and lower in the polar locales. Rain woodlands that have had wet atmospheres for quite a while have especially high biodiversity. Shockingly, earthly biodiversity
Volume 3 Issue 2 - 2019

\author{
Hiren B Soni \\ Department of Environmental Science \& Technology, Institute of \\ Science \& Technology for Advanced Studies \& Research, India
}

Correspondence: Hiren B Soni, P.G. Department of Environmental Science \& Technology (EST), Institute of Science \& Technology for Advanced Studies \& Research (ISTAR), Vallabh Vidyanagar - 388I20, Dist. Anand, Gujarat, India, Tel +91942602390I/88496I4554, Email drhirenbsoni@gmail.com

Received: January 27, 2018 | Published: April 17, 2019

is believed to be up to multiple times more prominent than sea biodiversity. ${ }^{17}$

There is an expansion in biodiversity from the poles to the tropics. Subsequently, territories at lower latitudes have a bigger number of animal groups than regions at higher latitudes. This is regularly alluded to as the latitudinal slope in species decent variety. A few biological components may add to the inclination, however a definitive factor behind a significant number of them is the more noteworthy mean temperature at the equator contrasted with that of the poles. ${ }^{18-20}$ The earthbound biodiversity decreases from the equator to the poles. ${ }^{21}$

\section{Hotspots}

A biodiversity hotspot is a region with an abnormal state of endemic species that have encountered incredible natural surroundings misfortune inside the most recent couple of decades, ${ }^{22-25}$ which are well spread everywhere throughout the world, the larger part are woodland regions and most are situated in the tropics. Brazil's Atlantic Forest, The island of Madagascar and India, and Colombia are portrayed by high biodiversity, with the most elevated rate of species by zone unit around the world, and have the biggest number of endemics (species that are not found normally anyplace else) of any nation. ${ }^{26}$

\section{Ecosystem services of biodiversity}

Ecosystem services are the suite of advantages that biological systems give to mankind. ${ }^{27}$ The normal species, or biota, are the overseers everything being equal. It seems as though the characteristic world is a colossal financial balance of capital resources equipped for paying life-supporting profits uncertainly, yet just if the capital is kept up. ${ }^{28}$ These services are: Provisioning services: involve the production of renewable resources (e.g.: food, wood, fresh water) Regulating services: lessen environmental change (e.g.: climate regulation, pest/disease control) and Cultural services: represent human value and enjoyment (e.g.: landscape aesthetics, cultural heritage, outdoor recreation and spiritual significance).$^{29}$

There have been numerous cases about biodiversity's impact on these ecosystem services, particularly provisioning and directing 
administrations. After a thorough overview through companion explored writing to assess 36 unique cases about biodiversity's impact on biological system administrations, 14 of those cases have been approved, six exhibit blended help or are unsupported, three are wrong, and 13 need enough proof to reach complete inferences. ${ }^{30}$

More species diversity of plants builds grain yield, ${ }^{27}$ by and large harvest yield, ${ }^{31}$ and that of trees expands in general wood generation (c, 2008). More species assorted diversity of fish builds the solidness of fisheries yield, ${ }^{27}$ and that of characteristic irritation adversaries diminishes herbivorous bug populaces. ${ }^{33-35}$ More noteworthy species diversity of plants diminishes sickness commonness on plants, ${ }^{36}$ builds protection from plant intrusion, ${ }^{36,37}$ and amazingly it expands carbon sequestration just for the transient time span. ${ }^{38}$ In addition, more prominent species diversity of plants builds soil supplement remineralization and soil natural issue. ${ }^{36}$

More noteworthy species diversity of plants might possibly diminish herbivorous nuisance populaces. Information from two separate audits proposes that more prominent species of plants diminishes pest populaces. ${ }^{36,39-41}$ More variety of creatures could possibly diminish illness pervasiveness on those creatures..$^{42}$ In spite of the fact that a recent report uncovered that biodiversity may in actuality improve sickness opposition inside creature networks, in any event in land and water proficient frog lakes. ${ }^{43}$ More noteworthy pollinator species might possibly expand fertilization, ${ }^{27}$ however a production from March 2013 recommends that expanded local pollinator assorted variety upgrades dust or pollen deposition. ${ }^{44}$ Contrastingly, plant species that are more prominent decreases primary production..$^{27}$ More noteworthy hereditary species of various life forms diminishes freshwater purification..$^{38}$

Since the Stone Age, species loss has quickened over the normal basal rate, driven by human action. Assessments of species loss are 100-10,000 times as quick as is regular in the fossil record. Biodiversity likewise manages numerous non-material advantages including profound and tasteful qualities, information frameworks and instruction. ${ }^{45}$

\section{Effects of biodiversity on human health}

Biodiversity's significance to human wellbeing is turning into a worldwide political issue, as logical proof expands on the worldwide wellbeing ramifications of biodiversity misfortune. ${ }^{46-48}$ This issue is firmly connected with the issue of environmental change, ${ }^{49}$ the same number of the foreseen wellbeing dangers of environmental change are related with changes in biodiversity (for example changes in populaces and appropriation of infection vectors, shortage of new water, impacts on horticultural biodiversity and sustenance assets and so on.). This is on the grounds that the species well on the way to vanish are those that cradle against irresistible malady transmission, while enduring species will in general be the ones that expansion illness transmission, for example, that of West Nile Virus, Lyme infection and Hantavirus. ${ }^{50}$

The developing interest and absence of drinkable water on the planet displays an extra test to the eventual fate of human wellbeing. Incompletely, the issue lies in the accomplishment of water providers to build supplies and disappointment of gatherings advancing protection of water assets. ${ }^{51}$ While the dispersion of clean water increments, in a few sections of the world it stays unequal. As indicated by the World Health Organization 2018, just $71 \%$ of the worldwide populace utilized a securely overseen drinking-water benefit. A portion of the medical problems affected by biodiversity incorporate dietary wellbeing and nourishment security, irresistible malady, restorative science and therapeutic assets, social and mental wellbeing. ${ }^{52}$ Biodiversity is likewise known to have an imperative job in lessening catastrophe hazard and in post-calamity help and recuperation endeavors. ${ }^{53-55}$

Biodiversity gives basic help to medicate revelation and the accessibility of therapeutic assets. ${ }^{56,57}$ A huge extent of medications are inferred, specifically or by implication, from organic sources: in any event half of the pharmaceutical mixes on the US showcase are gotten from plants, creatures and miniaturized scale life forms, while about $80 \%$ of the total populace relies upon prescriptions from nature (utilized in either present day or customary therapeutic practice) for essential social insurance..$^{47}$ Just a small portion of wild species has been examined for therapeutic potential. Biodiversity has been basic to progresses all through the field of bionics. Proof from market investigation and biodiversity science demonstrates that the decrease in yield from the pharmaceutical area since the mid1980 s can be ascribed to a move far from regular item investigation ("bioprospecting") for genomics and manufactured science. These are sure cases about the estimation of unfamiliar pharmaceuticals may not give enough motivating force to organizations in free markets to scan for them on account of the staggering expense of improvement. ${ }^{58}$ In the interim, characteristic items have a long history of supporting critical financial and wellbeing development. ${ }^{59,60}$ Marine environments are especially essential, ${ }^{61}$ albeit wrong bioprospecting can build biodiversity misfortune, just as abusing the laws of the networks and states from which the assets are taken. ${ }^{53,54,62,63}$

\section{Effects of biodiversity on business and industry}

Numerous mechanical materials get straightforwardly from organic sources. These incorporate building materials, filaments, colors, elastic, and oil. Biodiversity is additionally critical to the security of assets, for example, water, timber, paper, fiber and sustenance. ${ }^{64,65}$ Subsequently, biodiversity loss is a huge hazard factor in business improvement and a risk to long haul financial supportability ${ }^{66}$

\section{Leisure, cultural and aesthetic values of biodiversity}

Biodiversity advances relaxation exercises, for example, climbing, flying creature viewing or natural history study. Biodiversity motivates artists, painters, stone workers, scholars, and different artisans. Numerous societies see themselves as a vital piece of the normal world, which expects them to regard other living creatures. Well known practices, for example, cultivating, angle keeping and specimen gathering unequivocally rely upon biodiversity. The quantity of species associated with such interests is during the many thousands; however, the lion's share does not enter trade. The connections between the first regular territories of these outlandish creatures and plants and business authorities, providers, raisers, propagators and the individuals who advance their comprehension and satisfaction are unpredictable and ineffectively comprehended. General society reacts well to introduction to uncommon and unordinary life forms, mirroring their innate esteem. Rationally it could be contended that biodiversity has inherent tasteful and profound incentive to humankind all by itself. This thought can be utilized as a stabilizer to the idea that tropical backwoods and other natural domains are just deserving of preservation because of the administrations they give. ${ }^{67}$ 


\section{Ecological services of biodiversity}

Biodiversity bolsters numerous biological system administrations and networks that are progressively gainful, because they contain key species that affect profitability and contrasts in useful characteristics among living beings increment absolute asset catch. The effects of assorted variety loss on biological procedures may be adequately extensive to match the effects of numerous other worldwide drivers of natural change. Keeping up various biological community forms at numerous spots and times requires more elevated amounts of biodiversity than completes a solitary procedure at a solitary place and time. ${ }^{27}$ It has an impact in managing the science of our climate and water supply. Biodiversity is specifically associated with water purging, reusing supplements and giving rich soils. Trials with controlled conditions have demonstrated that people can only with significant effort manufacture environments to help human needs. ${ }^{68}$ For instance, creepy crawly fertilization can't be mirrored, however there have been endeavors to make counterfeit pollinators utilizing unmanned elevated vehicles. ${ }^{69}$ The financial action of fertilization alone spoke to between $\$ 2.1-14.6$ billion out of 2003 . $^{70,71}$

\section{A final thought: challenges ahead}

Investigating the present points of view on biological system benefits, an environmentalist need to recognize the impact of anthropogenic intercessions to propose practices to profit benefit giving creatures and related administrations. He ought to have the capacity to assess connections between markers of biological system benefits that are gathered in natural examinations while representing vulnerabilities of environmental procedures that underlie these administrations. The evaluation of biological system benefits on the use of sets of pointers that cover parts of administration giving units, environment the executives, and scene adjustment for a viable arranging and the executives ought to be considered. Restricted comprehension of the idea of connections among administrations and an absence of a general measurable system ought to be widened. To oversee biological community benefit provisioning, an environmentalist need to build up whether administrations react to a common driver or if administrations are specifically connected to one another. At long last, thinking about relating biodiversity to biological community benefits regularly center around administrations at little spatial or short fleeting scales, yet examine on the assurance of administrations is frequently coordinated toward administrations giving advantages everywhere spatial scales. Biological research needs to address a scope of spatial and fleeting scales to give a multifaceted comprehension of how nature advances human prosperity. Tending to these difficulties later on offers a special open door for environmentalists to go about as advertisers for the comprehension about how to save benefits picked up from nature.

\section{Acknowledgments}

Publication commitments have not been a straightforward assignment; it is a tedious job. It has been and still a genuine delight and unquestionably a remunerating knowledge filling in Biodiversity International Journal (BIJ) as an Associate Editor. I will do my best to confront all difficulties that stand up to the journal, endeavoring to expand its quality and its contents. I have been delighted in reviewing all the assigned manuscripts in this regard. Besides, I want to thank and offer my genuine thanks to the distributer, specialized staff, and the Editorial Board of Biodiversity International Journal for their incessant help and inputs, which are important to create and distribute this material of a high caliber. Subsequently, it is my pleasure to welcome all analysts in biodiversity and natural science to present their logical articles to Biodiversity International Journal. I render my blissful wishes to all authors, reviewers, editorial staff, and publishing team of BIJ to contribute more and more with accentuated zeal and zest to achieve sky-scrapping booming of BIJ with grand success!

\section{Conflicts of interest}

Author declares there is no conflict of interest in publishing the article.

\section{References}

1. UNEP. What is biodiversity? United Nations Environment Programme, World Conservation Monitoring Centre. 2002.

2. Gaston Kevin J. Global patterns in biodiversity. Nature. 2000;405(6783):220-227.

3. Field Richard, Hawkins Bradford A, Cornell Howard V, et al. Spatial species-richness gradients across scales: A meta-analysis. Journal of Biogeography. 2009;36(1):132-147.

4. Young Anthony. Global Environmental Outlook 3 (GEO-3): Past, Present and Future Perspectives. 2002;1-466.

5. Myers Norman, Mittermeier Russell A, Mittermeier Cristina G, et al. Biodiversity hotspots for conservation priorities. Nature. 2000;403(6772):853-858.

6. McPeek Mark A, Brown Jonathan M. Clade Age and Not Diversification Rate Explains Species Richness among Animal Taxa. $\mathrm{Am}$ Nat. 2007;169(4):97-106.

7. Peters Shanan. Sepkoski's Online Genus Database. University of Wisconsin-Madison. 2013.

8. Rabosky Daniel L. Ecological limits and diversification rate: Alternative paradigms to explain the variation in species richness among clades and regions. Ecol Lett. 2009;12(8):735-743.

9. Vignieri S. Vanishing Fauna(Special Issue). Science. 2014;345(6195):392412 .

10. Davis J. Introduction to Environmental Engineering. McGraw-Hill Education. 2011.

11. Tor Bjorn Larsson. Biodiversity evaluation tools for European forests. Ecological Bull. 2001;50:1-237.

12. Campbell AK. Save those molecules: molecular biodiversity and life. Journal of Applied Ecology. 2003;40(2):193-203.

13. Lefcheck Jon. What is functional diversity, and why do we care? Sample (Ecology). 2014.

14. Hawksworth DL, Harper JL. Biodiversity: Measurement and Estimation Philos Trans R Soc Lond B Biol Sci. 1994;345(1311):5-12.

15. Gaston Kevin J, Spicer John I. Biodiversity: An Introduction. Wiley. 2004.

16. Wilcox Bruce A. In situ conservation of genetic resources: determinants of minimum area requirements. 1984;18-30.

17. Benton MJ. Biodiversity on land and in the sea. Geological Journal. 2001;36(3-4):211-230.

18. Allen AP, Gillooly JF, Savage VM, et al. Kinetic effects of temperature on rates of genetic divergence and speciation. Proc Natl Acad Sci USA. 2006;103(24):9130-9135.

19. Currie DJ, Mittelbach GG, Cornell HV, et al. A critical review of speciesenergy theory. Ecology Letters. 2004;7(12):1121-1134. 
20. Mora C, Robertson DR. Causes of latitudinal gradients in species richness: A test with fishes of the Tropical Eastern Pacific. Ecology. 2005;86(7):17711782.

21. Hillebrand H. On the generality of the latitudinal diversity gradient. The American Naturalist. 2004;163(2):192-211.

22. Myers N. The biodiversity challenge: Expanded hot-spots analysis. Environmentalist. 1990;10(4):243-256.

23. Myers N. Threatened biotas: 'Hot spots' in tropical forests. Environmentalist. 1988;8(3):187-208.

24. McKee Jeffrey K. Sparing Nature: The Conflict Between Human Population Growth and Earth's Biodiversity. Rutgers University Press. 2004.

25. Tittensor DP, Camilo M, Walter J, et al. Global patterns and predictors of marine biodiversity across taxa. Nature. 2011;466(7310):1098-1101.

26. Galindo Leal, Carlos. The Atlantic Forest of South America: Biodiversity Status, Threats, and Outlook. Washington: Island Press. 2003.

27. Bradley J Cardinale, J Emmett Duffy, Andrew Gonzalez, et al. Biodiversity loss and its impact on humanity. Nature. 2012;486(7401):59-67.

28. Wright Richard T, Bernard J Nebel. Environmental Science : Toward a Sustainable Future. $8^{\text {th }}$ Ed. Upper Saddle River, NJ Pearson Education. 2002.

29. Terry C Daniel, Andreas Muhar, Arne Arnberger, et al. Contributions of cultural services to the ecosystem services agenda. Proceedings of the National Academy of Sciences. 2012;109(23):8812-8819.

30. Cazzolla Gatti R, Hordijk W, Kauffman S. Biodiversity is autocatalytic. Ecological Modelling. 2017;346:70-76.

31. Kiaer Lars P, Skovgaard M, Ostergard Hanne. Grain yield increase in cereal variety mixtures: A meta-analysis of field trials. Field Crops Research. 2009;114(3):361-373.

32. Piotto Daniel. A meta-analysis comparing tree growth in monocultures and mixed plantations. Forest Ecology and Management. 2008;255(34):781-786.

33. Futuyma Douglas J, Shaffer H Bradley, Simberloff Daniel. Annual Review of Ecology, Evolution and Systematics. 2009.

34. Philpott SM, Soong O, Lowenstein JH, et al. Functional richness and ecosystem services: Bird predation on arthropods in tropical agroecosystems. Ecol Appl. 2009;19(7):1858-1867.

35. Van Bael SA, Philpott SM, Greenberg R, et al. Birds as predators in tropical agroforestry systems. Ecology. 2008;89(4):928-934.

36. Quijas Sandra, Schmid Bernhard, Balvanera Patricia. Plant diversity enhances provision of ecosystem services: A new synthesis. Basic and Applied Ecology. 2010;11(7):582-593.

37. Levine Jonathan M, Adler Peter B, Yelenik Stephanie G. A metaanalysis of biotic resistance to exotic plant invasions. Ecology Letters. 2004;7(10):975-989.

38. Cardinale BJ, Matulich KL, Hooper DU, et al. The functional role of producer diversity in ecosystems. Am J Bot. 2011;98(3):572-592.

39. Andow DA. Vegetational Diversity and Arthropod Population Response. Annual Review of Entomology. 1991;36(1):561-586.

40. Crowder David W, Tobin D Northfield, Michael R Strand, et al. Organic agriculture promotes evenness and natural pest control. Nature. 2010;466(7302):109-112.

41. Letourneau DK, Armbrecht I, Rivera BS, et al. Does plant diversity benefit agroecosystems? A synthetic review. Ecol Appl. 2011;21(1):9-21.
42. Keesing Felicia, Lisa K Belden, Peter Daszak, et al. Impacts of biodiversity on the emergence and transmission of infectious diseases. Nature. 2010;468(7324):647-652.

43. Johnson Pieter TJ, Daniel L Preston, Jason T Hoverman, et al. Biodiversity decreases disease through predictable changes in host community competence. Nature. 2013;494(7436):230-233.

44. Lucas A Garibaldi, Ingolf Steffan Dewenter, Rachael Winfree, et al. Wild Pollinators Enhance Fruit Set of Crops Regardless of Honey Bee Abundance. Science. 2013;339(6127):1608-1611.

45. Hassan Rashid M. Ecosystems and human well-being: current state and trends: findings of the Condition and Trends Working Group of the Millennium Ecosystem Assessment. Island Press. 2006.

46. WHO, CBD. Connecting Global Priorities: Biodiversity and Human Health, a State of Knowledge Review. World Health Organization and Secretariat of the Convention on Biological Diversity. 2015.

47. Chivian Eric. Sustaining Life: How Human Health Depends on Biodiversity. OUP US. 2008.

48. Corvalán Carlos, Hales Simon, Anthony J McMichael. Ecosystems and Human Well-being: Health Synthesis. World Health Organization. 2005.

49. CBD. Climate Change and Biological Diversity. Convention on Biological Diversity. 2009.

50. Ramanujan, Krishna. Study: Loss of species is bad for your health. Cornell Chronicle. 2010.

51. The World Bank. Water and Development: An Evaluation of World Bank Support, 1997-2007. World Bank Publications. 2010.

52. Gaston Kevin J, Warren Philip H, Devine Wright, et al. Psychological benefits of greenspace increase with biodiversity. Biology Letters. 2007;3(4):390-394

53. COHAB. Natural Products and Medicinal Resources. Cohabnet.org. 2009.

54. COHAB. Biodiversity and Human Health - The issues. Cohabnet.org. 2009.

55. World Wildlife Fund (WWF). Arguments for Protection. 2011

56. GMO. Molecular Pharming. GMO Compass. GMOcompass.org, 2006.

57. Mendelsohn Robert, Balick Michael J. The value of undiscovered pharmaceuticals in tropical forests. Economic Botany. 1995;49(2):223228.

58. Mendelsohn Robert, Balick Michael J. Notes on economic plants. Economic Botany. 1997;51(3):328

59. Harvey Alan L. Natural products in drug discovery. Drug Discovery Today. 2008;13(19-20):894-901.

60. Hawkins ES, Reich Reich MR. Japanese-originated pharmaceutical products in the United States from 1960 to 1989: an assessment of innovation. Clin Pharmacol Ther. 1992;51(1):1-11.

61. Roopesh J, Shailendra Sonawane, Noopur Mandrekar. Marine organisms: Potential Source for Drug Discovery. Current Science. 2008;94(3):292.

62. Cole A. Looking for new compounds in sea is endangering ecosystem. Biomedical Journal. 2005;330(7504):1350.

63. Dhillion SS, Svarstad H, Amundsen C, et al. Bioprospecting: Effects on environment and development. Ambio. 2002;31(6):491-493

64. IUCN, WRI. Business and Ecosystems: Ecosystem Challenges and Business Implications. World Business Council for Sustainable Development, Earthwatch Inst. 2007. 
65. MEA. Ecosystems and Human Well-being: Opportunities and Challenges for Business and Industry. Millennium Ecosystem Assessment. 2005.

66. WRI. Corporate Ecosystem Services Review. 2009.

67. Tribot A, Mouquet N, Villeger S, et al. Taxonomic and functional diversity increase the aesthetic value of coralligenous reefs. Scientific Reports. 2016;6:34229.

68. Broad William. Paradise Lost: Biosphere Retooled as Atmospheric Nightmare. The New York Times. 1996.
69. Ponti Crystal. Rise Of The Robot Bees: Tiny Drones Turned Into Artificial Pollinators. NPR. 2017

70. Losey John E, Vaughan Mace. The Economic Value of Ecological Services Provided by Insects. Bioscience. 2006;56(4):311.

71. Bass MS, Finer M, Jenkins CN, et al. Global Conservation Significance of Ecuador's Yasuní National Park. PLoS One. 2010;19;5(1):8767. 